\title{
IMPLEMENTASI METODE ALTMAN Z-SCORE UNTUK MEMPREDIKSI KEBANGKRUTAN PERUSAHAAN
}

\author{
Mochamad Kohar Mudzakar \\ Program Studi Akuntansi Universitas Widyatama Bandung \\ Email : kohar.mudzakar@widyatama.ac.id
}

\begin{abstract}
The study of bankruptcy in companies listed in the LQ-45 index is intended to measure and predict financial incompetence using the Altman Z-Score method. The study was conducted on 19 companies as samples taken based on purposive sampling technique, based on the criteria that the company regularly reports their financial reports from 2010 to 2013. The investigation method used is descriptive to describe and measure the bankruptcy of a company. The result shows that companies that met the healthy category in 2010 were 15 companies and in 2011-2013 there were 14 companies. The 2010 vulnerable categories included 3 companies, in 2011-2012 there were 4 companies, and in 2013 there were 2 companies. For the bankrupt category in 2010-2012 there were 1 company, and in 2013 there were 3 companies.
\end{abstract}

Keywords : Bankruptcy, Altman Z-Score, LQ-45, Bankruptcy Potency, Financial Ratio Value.

\begin{abstract}
ABSTRAK
Studi menyangkut kebangkrutan pada perusahaan yang terdaftar dalam indeks LQ-45 ditujukan untuk mengukur dan memprediksi ketidakmampuan finansial dengan metode Altman Z-Score. Studi dilakukan pada 19 perusahaan sebagai sampel yang diambil berdasarkan teknik purposive sampling, didasarkan pada kriteria perusahaan secara konstan melaporkan laporan keuangan dari 2010-2013. Metode investigasi yang digunakan adalah deskriptif untuk menggambarkan dan mengukur kebangkrutan perusahaan. Hasil penelitian menunjukan perusahaan yang memenuhi kategori sehat pada tahun 2010 sebanyak 15 perusahaan dan tahun 2011-2013 sebanyak 14 perusahaan. Kategori rawan tahun 2010 sebanyak 3 perusahaan, tahun 2011-2012 sebanyak 4 perusahaan, dan tahun 2013 sebanyak 2 perusahaan. Untuk kategori bangkrut tahun 2010-2012 sebanyak 1 perusahaan, dan tahun 2013 sebanyak 3 perusahaan.
\end{abstract}

Kata kunci: Kebangkrutan, Altman Z-Score, LQ-45.

\section{PENDAHULUAN \\ Latar Belakang}

Pada umumnya perusahaan terbuka memanfaatkan keberadaan pasar modal sebagai sarana untuk mendapatkan sumber dana. Adanya pasar modal dapat dijadikan sebagai alat untuk mereflesikan kinerja dan kondisi keuangan perusahaan melalui peningkatan harga saham perusahaan jika kondisi keuangan dan kinerja perusahaan baik. Para investor dan kreditur sebelum menanamkan dananya pada suatu perusahaan akan selalu melihat terlebih dahulu kondisi keuangan perusahaan tersebut (Atmini \& Wuryan, dalam Fatmawati 2012).

Salah satu pertimbangan investor dalam melihat posisi pasar modal adalah dengan melihat perusahaan yang terdaftar pada indeks saham LQ-45, yaitu kelompok saham perusahaan dengan likuiditas dan kapitalisasi pasar yang tinggi dan terdiri dari perusahaan yang telah melewati beberapa seleksi dan telah memenuhi kriteria. Perusahaan yang termasuk ke dalam LQ-45 memiliki laporan keuangan yang baik karena menunjukkan prospek pertumbuhan yang baik pula, selain itu ada beberapa perusahaan yang selama beberapa periode tetap berada pada LQ-45. Hal ini menunjukkan bahwa investasi jangka panjang pada perusahaan tersebut dapat menjanjikan bagi investor (Rizkia, 2013).

Pada kenyataannya listing pada LQ-45 belum menjamin kesehatan keuangan perusahaan. Meski terbilang saham unggulan, analis mengingatkan, berinvestasi di saham LQ-45 tidak memberi jaminan untung dibanding saham non LQ-45. Sebab ketika pasar terkena 
sentimen negatif, saham LQ-45 justru paling terkena tekanan jual (Reza). Beberapa saham non LQ-45 bisa lebih bertahan terhadap penurunan harga.

Salah satu perusahaan yang listing di LQ-45 yaitu PT. Bumi Resources menggegerkan para pemegang saham akibat aksi jual yang mengakibatkan saham raksasa batu bara itu sudah minus 20 poin $(2,63 \%)$ ke Rp 740 dalam waktu kurang dari 2 jam sejak pembukaan saham dengan harga Rp 760 (www.kontan.co.id). Salah satu indikator performa keuangan semester I 2012 yang sangat buruk dimana solvabilitas emiten sangat lemah. Pada periode tersebut BUMI mencatatkan kerugian sebesar US\$ 322 juta, padahal dalam waktu yang sama meraup untung US\$232 juta.

Informasi kinerja keuangan BUMI yang merah dan faktor eksternal seperti penurunan harga jual batu bara akibat krisis global, berimbas terhadap turunnya indeks harga saham BUMI yang ditunjukkan dalam grafik di bawah ini.

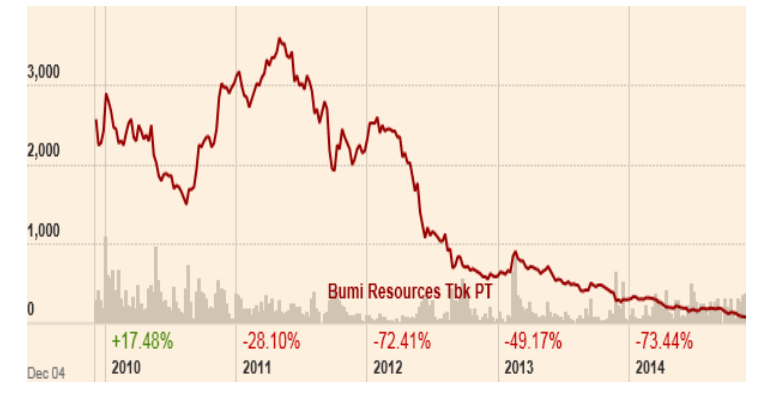

\section{Gambar 1. Informasi Kinerja Keuangan \\ Sumber: www.market.ft.com}

Atas dasar fenomena tersebut dengan gejala kesulitan keuangan , maka diperlukan sebuah analisa khusus untuk memprediksi kebangkrutan dengan menganalisa laporan keuangan. Semakin awal tanda-tanda kebangkrutan diketahui, semakin baik bagi manajemen karena dapat segera melakukan perbaikan. Pihak kreditur dan pemegang saham bisa segera mengatasinya dari berbagai macam kemungkinan yang buruk.

Untuk mengukur kinerja keuangan suatu perusahaan dapat menggunakan analisis rasio keuangan (Munawir, 2004). Sedangkan untuk memprediksi kebangkrutan suatu perusahaan model yang cukup terkenal digunakan dan menjadi pionir adalah model Altman Z-Score (1968) (Hanafi, 2012).

Dalam penelitian Firda dan Saifi (2012) menyebutkan bahwa dalam memprediksi kebangkrutan Altman menggunakan lima rasio keuangan yang diperuntukkan bagi perusahaan terbuka. Dari hasil perhitungan akan diperoleh nilai Z-Score yang dapat menggambarkan posisi keuangan perusahaan sedang dalam kondisi sehat, rawan, dan bangkrut. Kesulitan keuangan dan tanda-tanda awal kebangkrutan dapat diketahui melalui analisis terhadap data dalam laporan keuangan.

Tujuan penelitian adalah untuk mengetahui prediksi kebangkrutan perusahaan yang terdaftar dalam Indeks LQ-45 secara konstan pada tahun 2010-2013 dengan menggunakan metode Altman Z-Score.

\section{Kajian Pustaka}

Laporan Keuangan

Laporan keuangan adalah suatu penyajian terstruktur dari posisi keuangan dan kinerja keuangan suatu perusahaan. Tujuan laporan keuangan adalah memberikan informasi mengenai posisi keuangan, kinerja keuangan, dan arus kas perusahaan yang bermanfaat bagi sebagian besar pengguna laporan keuangan dalam pembuatan keputusan ekonomik. 
Laporan keuangan juga menunjukkan hasil pertanggungjawaban manajemen atas penggunaan sumberdaya yang dipercayakan kepada mereka (PSAK No. 1 tahun 2012). Analisis Rasio Keuangan

Analisis rasio keuangan adalah menguraikan pos-pos laporan keuangan menjadi unit informasi yang lebih kecil dan melihat hubungannya yang bersifat signifikan atau yang mempunyai makna antara satu dengan yang lain baik antara data kuantitatif maupun non kuantitatif dengan tujuan untuk mengetahui kondisi keuangan lebih dalam yang sangat penting dalam proses menghasilkan keputusan yang tepat (Harahap, 2004). Salah satu cara dalam analisis laporan keuangan adalah menggunakan analisis rasio, yaitu suatu metode analisis untuk mengetahui hubungan dari pos-pos tertentu dalam neraca atau laporan laba-rugi secara individu atau kombinasi dari kedua laporan tersebut (Munawir, 2004).

Analisis rasio keuangan adalah metode yang lebih spesifik dengan menitikberatkan pada analisis laporan neraca dan laba-rugi, dilakukan penelaahan dan pencarian hubungan antar pos-pos tertentu sehingga didapatkan suatu hasil yang diinginkan dan digunakan menjadi sumber informasi dalam pengambilan keputusan. Analisis rasio keuangan digunakan dalam memprediksi kebangkrutan perusahaan adalah rasio likuiditas, profitabilitas, solvabilitas, aktivitas, dan nilai pasar.

Kebangkrutan

Kebangkrutan merupakan kondisi dimana perusahaan tidak mampu lagi untuk melunasi kewajibannya (Toto, 2011). Kondisi ini biasanya tidak muncul begitu saja di perusahaan, ada indikasi awal dari perusahaan tersebut yang biasanya dapat dikenali lebih dini jika laporan keuangan dianalisis secara lebih cermat dengan analisis rasio keuangan.

Dalam kaitannya dengan kesehatan keuangan dan potensi kebangkrutan perusahaan, Munawir (2004) mengelompokkan menjadi empat kategori:

1. Perusahaan yang tidak mengalami kesulitan keuangan (posisi keuangan jangka pendek maupun jangka panjang sehat).

2. Perusahaan yang mengalami kesulitan keuangan (jangka pendek) dan manajemennya berhasil mengatasi dengan baik sehingga tidak failit (bangkrut).

3. Perusahaan yang tidak mengalami kesulitan keuangan tetapi menghadapi kesulitan yang bersifat non keuangan sehingga diambil keputusan menyatakan failit.

4. Perusahaan yang mengalami kesulitan keuangan dan manajemen tidak berhasil mengatasinya sehingga akhirnya jatuh failit.

Kesimpulannya kebangkrutan merupakan kondisi perusahaan yang tidak sehat dalam melanjutkan usahanya dikarenakan ketidakmampuan dalam bersaing, sehingga mengakibatkan penurunan profitabilitas.

Cara Mendeteksi dan Meramalkan Kebangkrutan

Kemampuan dalam memprediksi kebangkrutan akan memberikan keuntungan banyak pihak, terutama kreditur dan investor(Darsono dan Ashari, 2005). Prediksi kebangkrutan juga berfungsi memberikan panduan tentang kinerja keuangan perusahaan apakah akan mengalami kesulitan keuangan atau tidak di masa mendatang.

Sebagai pihak di luar perusahaan, investor sebaiknya memiliki pengetahuan tentang kebangkrutan sehingga keputusan yang diambil tidak salah. Salah satu indicator untuk mengetahui kebangkrutan adalah indicator keuangan. Prediksi kesulitan keuangan dikemukakan oleh Edward Altman yang disebut dengan Altman Z-Score. Rumus Z-Score menggunakan komponen lqaporan keuangan sebagai alat prediksi terhadap kemungkinan bangkrut tidaknya perusahaan. 
Kesimpulannya dalam memprediksi kebangkrutan atau untuk mengetahui kondisi keuangan perusahaan di masa yang akan dating, dapat digunakan komponen rasio dalam rumus Z-Score sebagai alat prediksi terhadap kemungkinan bangkrut tidaknya suatu perusahaan.

Sejumlah studi telah dilakukan untuk mengetahui kegunaan analisis rasio keuangan dalam memprediksi kegagalan perusahaan, salah satu studi adalah Multiple Discriminant Analysis yang dilakukan oleh Edward Altman (Hanafi, 2004). Altman menggunakan lima jenis rasio, yaitu Working Capital to Total Assets, Retained Earning to Total Assets, Earning Before Interest and Taxes, Market Value of Equity to Book Value of Total Debt dan sales ti to Total Assets.

Secara matematis persamaan Altman Z-Score dapat dirumuskan sebagai berikut:

$$
\mathrm{Z}=1,2 \mathrm{X} 1+1,4 \mathrm{X} 2+3,3 \mathrm{X} 3+0,6 \mathrm{X} 4+1,0 \mathrm{X} 5 \text {. }
$$

Dimana : X1: Working Capital to Total Asset (Modal Kerja : Total Aktiva).

X2: Retained Earning to Total Asset (Laba ditahan : Total Aktiva)

X3: Earning Before Interest and Taxes to Total Asset (EBIT : Total Aktiva).

X4: Market Value of Equity to Book Value of Debt (Nilai Pasar Modal : Nilai Buku

Hutang).

X5: Sales to Total Asset (Penjualan : Total Aktiva).

Tabel 1. Hasil Perhitungan Nilai Z-Score sebagai berikut:

\begin{tabular}{|l|l|}
\hline Nilai Z-Score & Interpretasi \\
\hline $\mathrm{Z}>2,99$ & $\begin{array}{l}\text { Perusahaan tidak mengalami masalah dengan kondisi } \\
\text { keuangan (Sehat) }\end{array}$ \\
\hline $1,81<\mathrm{Z}<2,99$ & $\begin{array}{l}\text { Perusahaan akan mengalami permasalahan keuangan jika } \\
\text { tidak melakukan perbaikan yang berarti dalam manajemen } \\
\text { maupun struktur keuangan (Rawan Bangkrut) }\end{array}$ \\
\hline $\mathrm{Z}<1,81$ & $\begin{array}{l}\text { Perusahaan mengalami masalah keuangan yang serius } \\
\text { (Bangkrut) }\end{array}$ \\
\hline
\end{tabular}

Sumber: Hanafi, 2012

\section{METODE PENELITIAN}

Metode investigasi yang dipakai yaitu teori deskriptif untuk menggambarkan dan mengukur kebangkrutan perusahaan. Tujuan penelitian deskriptif adalah untuk membuat gambaran secara sistematis, aktual dan akurat mengenai fakta-fakta, sifat-sifat serta hubungan antara fenomena yang diselidiki.

Populasi penelitian adalah perusahaan yang termasuk dalam indeks saham LQ-45 secara konstan sejak tahun 2010-2013. Pemilihan sampel secara purposive sampling dengan tujuan untuk memperoleh sampel yang representatif berdasarkan kriteria yang ditentukan. Penentuan kriteria sampel diperlukan untuk menghindari timbulnya kesalahan dalam penentuan sampel penelitian, yang selanjutnya akan berpengaruh terhadap hasil analisis. Sampel penelitian yang diambil berdasarkan kriteria berikut:

1. Perusahaan yang termasuk dalam indeks saham LQ-45

2. Perusahaan yang termasuk dalam indeks saham LQ-45 secara kontinyu dari tahun 2010-2013.

3. Perusahaan selain sektor keuangan.

Jumlah sampel yang digunakan dalam penelitian adalah 19 perusahaan. Sampel penelitian dapat dilihat pada tabel 2 di bawah ini: 
Tabel 2. Daftar Sampel Perusahaan Tahun 2010-2013 di Indeks Saham LQ-45

\begin{tabular}{|c|c|c|}
\hline No & Kode & Nama Perusahaan \\
\hline 1 & AALI & Astra Agro Lestari Tbk. \\
\hline 2 & ADRO & Adaro Energy Tbk. \\
\hline 3 & ASII & Astra International Tbk. \\
\hline 4 & BUMI & Bumi Resources Tbk. \\
\hline 5 & GGRM & Gudang Garam Tbk. \\
\hline 6 & INCO & Indofood Sukses Makmur Tbk. \\
\hline 7 & INDF & Indo Tambangraya Megah Tbk. \\
\hline 8 & ITMG & Indocement Tunggal Prakasa Tbk. \\
\hline 9 & INTP & Jasa Marga (Persero) Tbk. \\
\hline 10 & JSMR & Kalbe Farma Tbk. \\
\hline 11 & KLBF & Lippo Karawaci Tbk. \\
\hline 12 & LPKR & PP London Sumatra Indonesia Tbk. \\
\hline 13 & LSIP & Perusahaan Gas Negara Tbk. \\
\hline 14 & PGAS & Tambang Batubara Bukit Asam Tbk. \\
\hline 15 & PTBA & Semen Indonesia Tbk \\
\hline 16 & SMGR & Telekomunikasi Indonesia Tbk. \\
\hline 17 & TLKM & Unilever Indonesia Tbk. \\
\hline 18 & UNTR & \\
\hline 19 & UNVR & \\
\hline
\end{tabular}

Teknik Analisis Data

Tahap-tahap analisis data yang dilakukan adalah:

1. Memperoleh data yang diperlukan yaitu laporan keuangan yang sudah diolah dalam bentuk ringkasan kinerja perusahaan yang termasuk dalam indeks LQ-45, yaitu 20102013

2. Menghitung rasio keuangan dengan menggunakan model Altman Z-Score.

3. Menghitung nilai model Altman Z-Score dari rasio keuangan yang telah diketahui, rumusnya adalah: $\mathrm{Z}=1,2 \mathrm{X} 1+1,4 \mathrm{X} 2+3,3 \mathrm{X} 3+0,6 \mathrm{X} 4+1,0 \mathrm{X} 5$

4. Melakukan interpretasi nilai hasil perhitungan model Altman Z-Score.

Interpretasi nilai Z-Score:

a. Z-Score > 2,99: perusahaan sehat.

b. Z-Score $=1,81-2,99$ : perusahaan rawan bangkrut.

c. Z-Score $<1,81$ : perusahaan potensial bangkrut.

5. Berdasarkan hasil data yang diperoleh dari analisis data tersebut kemudian ditarik kesimpulan.

\section{HASIL DAN PEMBAHASAN}

\section{Prediksi Kebangkrutan}

Setelah diperoleh nilai rasio keuangan WCTA (X1), RETA (X2), EBITTA (X3), MVEBVTL (X4), STA (X5) dari masing-masing perusahaan, langkah selanjutnya adalah melakukan perhitungan Z-Score dari hasil interpretasi nilai rasio tersebut. Selanjutnya nilai Z-Score dibandingkan dengan kriteria yang telah ditetapkan Altman agar dapat memprediksi kondisi kesehatan keuangan dari masing-masing perusahaan, maka hasil perhitungan Altman Z-Score sebagai berikut: 
Tabel 3. Nilai Z-Score Perusahaan termasuk Indeks LQ-45 Tahun 2010-2013

\begin{tabular}{|l|l|l|l|l|l|l|l|l|l|}
\hline \multirow{2}{*}{ No } & Kode & \multicolumn{9}{|c|}{ Z-Score } \\
\cline { 3 - 10 } & & 2010 & \multicolumn{9}{|c|}{2012} & 2013 \\
\hline 1 & AALI & 21,79 & Sehat & 14,69 & Sehat & 8,78 & Sehat & 7,14 & Sehat \\
\hline 2 & ADRO & 3,52 & Sehat & 2,80 & Rawan & 2,08 & Rawan & 1,54 & Bangkrut \\
\hline 3 & ASII & 4,86 & Sehat & 4,57 & Sehat & 4,18 & Sehat & 3,46 & Sehat \\
\hline 4 & BUMI & 1,63 & Bangkrut & 1,38 & Bangkrut & 0,14 & Bangkrut & $-0,57$ & Bangkrut \\
\hline 5 & GGRM & 8,21 & Sehat & 7,90 & Sehat & 7,30 & Sehat & 4,87 & Sehat \\
\hline 6 & INCO & 8,89 & Sehat & 5,43 & Sehat & 3,89 & Sehat & 3,74 & Sehat \\
\hline 7 & INDF & 2,86 & Rawan & 2,89 & Rawan & 2,99 & Rawan & 2,25 & Rawan \\
\hline 8 & ITMG & 17,61 & Sehat & 13,36 & Sehat & 9,89 & Sehat & 6,91 & Sehat \\
\hline 9 & INTP & 18,56 & Sehat & 18,62 & Sehat & 18,06 & Sehat & 15,27 & Sehat \\
\hline 10 & JSMR & 1,98 & Rawan & 2,16 & Rawan & 2,06 & Rawan & 1,64 & Bangkrut \\
\hline 11 & KLBF & 19,76 & Sehat & 15,59 & Sehat & 19,69 & Sehat & 16,10 & Sehat \\
\hline 12 & LPKR & 2,34 & Rawan & 2,41 & Rawan & 2,48 & Rawan & 2,10 & Rawan \\
\hline 13 & LSIP & 12,80 & Sehat & 12,58 & Sehat & 9,68 & Sehat & 7,76 & Sehat \\
\hline 14 & PGAS & 5,84 & Sehat & 5,47 & Sehat & 6,78 & Sehat & 5,25 & Sehat \\
\hline 15 & PTBA & 16,85 & Sehat & 10,33 & Sehat & 7,76 & Sehat & 5,70 & Sehat \\
\hline 16 & SMGR & 12,99 & Sehat & 10,92 & Sehat & 9,17 & Sehat & 8,15 & Sehat \\
\hline 17 & TLKM & 4,37 & Sehat & 4,31 & Sehat & 4,39 & Sehat & 4,44 & Sehat \\
\hline 18 & UNTR & 6,38 & Sehat & 5,39 & Sehat & 4,81 & Sehat & 4,01 & Sehat \\
\hline 19 & UNVR & 20,75 & Sehat & 16,88 & Sehat & 16,16 & Sehat & 17,36 & Sehat \\
\hline Sehat & 15 & $79 \%$ & 14 & $74 \%$ & 14 & $74 \%$ & 14 & $74 \%$ \\
\hline Rawan & 3 & $16 \%$ & 4 & $21 \%$ & 4 & $21 \%$ & 2 & $11 \%$ \\
\hline Bangkrut & 1 & $5 \%$ & 1 & $5 \%$ & 1 & $5 \%$ & 3 & $15 \%$ \\
\hline Jumlah & 19 & $100 \%$ & 19 & $100 \%$ & 19 & $100 \%$ & 19 & $100 \%$ \\
\hline
\end{tabular}

Sumber: Laporan Keuangan (diolah)

Kesimpulannya bahwa tahun 2010-2013 sebanyak 19 perusahaan yang konstan dalam indeks LQ-45. Tahun 2010, kategori sehat sebanyak 15 perusahaan $(79 \%)$, rawan bangkrut sebanyak 3 perusahaan (16\%), potensial bangkrut sebanyak 1 perusahaan (5\%). Tahun 2011, dan 2012, kategori sehat sebanyak 14 perusahaan, dan kategori rawan bangkrut sebanyak 4 perusahaan, dan potensial bangkrut sebanyak 1 perusahaan. Tahun2013 kategori sehat sebanyak 14 perusahaan, kategori rawan bangkrut sebanyak 2 perusahaan, dan potensial bangkrut sebanyak 3 perusahaan.

Adapun rinciannya sebagai berikut:

1. Sehat.

Tahun 2010-2013 sebanyak 14 perusahaan, yaitu AALI, ASII, GGRM, INCO, ITMG, INTP, KLBF, LSIP, PGAS, PTBA, SMGR, TLKM, UNTR, UNVR, dan ADRO dalam kategori sehat hanya tahun 2010.

Perusahaan tersebut berada dalam kondisi sehat disebabkan dinilai mampu menjalankan kegiatan operasional dengan baik, dimana perusahaan memiliki rasio keuangan WCTA, RETA, EBITTA, MVEBVTL, STA yang cukup baik. Contoh, UNVR memiliki nilai WCTA terkecil/ likuiditas di bawah rata-rata pada tahun 2010-2012, namun UNVR memiliki nilai EBITTA dan STA terbesar, artinya dalam penciptaan profitabilitas dan menjalankan aktivitas operasi dinilai baik. Nilai RETA 
dan MVEBVTL, cukup baik, sehingga membawanya ke dalam kategori sehat yang ditandai dengan nilai Z-Score di atas 2,99.

2. Rawan.

Tahun 2010-2012 sebanyak 1 perusahaan, yaitu JSMR, tahun 2010-2013 sebanyak 2 perusahaan, yaitu INDF, LPKR, dan tahun 2011-2012 sebanyak 1 perusahaan, yaitu ADRO.

3. Bangkrut.

Tahun 2010-2013 sebanyak 1 perusahaan, yaitu BUMI, dan tahun 2013 sebanyak 2 perusahaan, yaitu ADRO dan JSMR.

Perusahaan kategori potensial bangkrut ditandai nilai Z-Score $<1,81$, yaitu BUMI karena nilai WCTA, RETA, dan EBITTA cenderung menurun bahkan negatif tahun 2012 dan 2013, juga rasio MVEBVTL menurun, kecuali STA cukup berfluktuatif, namun tetap tidak membawa perusahaan menuju kategori yang lebih baik. Tahun 2013 ke 5 rasio JSMR mengalami penurunan nilai Z-Score nya $<1,81$. Berbeda dengan ADRO yang memiliki rasio WCTA dan RETA yang naik dari tahun sebelumnya, namun tidak didukung dengan rasio lainnya yang menurun, dan menyebabkan ADRO pada kategori potensial bangkrut.

Hasil Prediksi Kebangkrutan

Hasil prediksi kebangkrutan perusahaan yang termasuk indeks LQ-45 sebagai berikut.

Tabel 4. Prediksi Kebangkrutan Altman Perusahaan yang termasuk di LQ-45 Tahun 2010-2013

\begin{tabular}{|l|l|l|l|l|l|}
\hline \multirow{2}{*}{ Ko } & Kode & \multicolumn{4}{|c|}{ Z-Score } \\
\cline { 3 - 6 } & & 2010 & 2011 & 2012 & 2013 \\
\hline 1 & AALI & Sehat & Sehat & Sehat & Sehat \\
\hline 2 & ADRO & Sehat & Rawan & Rawan & Bangkrut \\
\hline 3 & ASII & Sehat & Sehat & Sehat & Sehat \\
\hline 4 & BUMI & Bangkrut & Bangkrut & Bangkrut & Bangkrut \\
\hline 5 & GGRM & Sehat & Sehat & Sehat & Sehat \\
\hline 6 & INCO & Sehat & Sehat & Sehat & Sehat \\
\hline 7 & INDF & Rawan & Rawan & Rawan & Rawan \\
\hline 8 & ITMG & Sehat & Sehat & Sehat & Sehat \\
\hline 9 & INTP & Sehat & Sehat & Sehat & Sehat \\
\hline 10 & JSMR & Rawan & Rawan & Rawan & Bangkrut \\
\hline 11 & KLBF & Sehat & Sehat & Sehat & Sehat \\
\hline 12 & LPKR & Rawan & Rawan & Rawan & Rawan \\
\hline 13 & LSIP & Sehat & Sehat & Sehat & Sehat \\
\hline 14 & PGAS & Sehat & Sehat & Sehat & Sehat \\
\hline 15 & PTBA & Sehat & Sehat & Sehat & Sehat \\
\hline 16 & SMGR & Sehat & Sehat & Sehat & Sehat \\
\hline 17 & TLKM & Sehat & Sehat & Sehat & Sehat \\
\hline 18 & UNTR & Sehat & Sehat & Sehat & Sehat \\
\hline 19 & UNVR & Sehat & Sehat & Sehat & Sehat \\
\hline Sehat & & 15 & 14 & 14 & 14 \\
\hline
\end{tabular}




\begin{tabular}{|l|l|l|l|l|}
\hline Rawan & 3 & 4 & 4 & 2 \\
\hline Bangkrut & 1 & 1 & 1 & 3 \\
\hline
\end{tabular}

Tahun 2010 kategori sehat sebanyak 15 perusahaan, rawan sebanyak 3 perusahaan, dan potensi bangkrut sebanyak 1 perusahaan. Tahun 2011-2012 kategori sehat sebanyak 14 perusahaan, rawan sebanyak 4 perusahaan, dan potensi bangkrut sebanyak 1 perusahaan. Tahun 2013 kategori sehat sebanyak 14 perusahaan, rawan sebanyak 2 perusahaan, dan potensi bangkrut sebanyak 3 perusahaan.

\section{KESIMPULAN DAN SARAN}

Prediksi kebangkrutan perusahaan yang termasuk dalam LQ-45 sebagai berikut:

1. Tahun 2010 kategori sehat sebanyak 15 perusahaan, rawan sebanyak 3 perusahaan, dan potens bangkrut 1 perusahaan.

2. Tahun 2011 kategori sehat sebanyak 14 perusahaan, dan rawan sebanyak 5 perusahaan.

3. Tahun 2012 kategori sehat sebanyak 14 perusahaan, rawan sebanyak 4 perusahaan, dan potensi bangkrut sebanyak 1 perusahaan.

4. Tahun 2013 kategori sehat sebanyak 14 perusahaan, rawan sebanyak 2 perusahaan, dan potensi bangkrut sebanyak 3 perusahaan.

\section{Keterbatasan}

Keterbatasan dalam penelitian ini adalah:

1. Jumlah sampel dan periode terbatas hanya tahun $2010-2013$.

2. Perusahaan delisted yang dijadikan sampel hanya perusahaan yang sudah terdapat di Bursa Efek selama 4 tahun.

3. Penelitian ini hanya menggunakan 1 model prediktor delisting, sedangkan masih ada model prediktor delisting lainnya yang sudah ditemukan.

\section{Implikasi}

Implikasi hasil penelitian ditujukan untuk kontribusi terhadap literatur, perusahaan, dan ivestor, secara lebih terperinci yakni:

1. Kontribusi Terhadap Literatur

Model Altman (Z-Score) yang paling akurat dalam memprediksi perusahaan delisting. Dengan penelitian ini, diharapkan dapat lebih memperkaya pengetahuan mengenai analisis prediksi delisting, dan hasilnya menjadi referensi untuk penelitian selanjutnya.

2. Bagi Perusahaan

Dengan memperhatikan hasil dari penelitian maka diharapkan perusahaan lebih dapat memahami analisis dari prediksi delisting pada perusahaan, sehingga nantinya akan membantu perusahaan di dalam pengambilan keputusan, agar perusahaan terhindar dari kebangkrutan.

3. Bagi Investor

Berdasarkan hasil penelitian ini dapat membantu investor dalam menganalisis dan memutuskan apakah akan melakukan investasi pada suatu perusahaan atau tidak. Dengan adanya hasil penelitian ini, maka diharapkan dapat membantu investor untuk dapat melihat potensi delisting pada suatu perusahaan, sehingga keputusan investasi menjadi semakin baik.

\section{Saran}

1. Sehat, dapat mempertahankan dan tetap memperhatikan segala aspek yang mempengaruhi perusahaan tersebut dan melakukan pencegahan agar tidak bangkrut.

2. Rawan, harus meningkatkan kinerja perusahaannya agar tidak mengalami penurunan yang dapat menyebabkan kebangkrutan. 
3. Potensi bangkrut, sebaiknya manajemen lebih memperhatikan asetnya, sehingga tidak terjadi over investment dan lebih produktif dalam menghasilkan laba.

\section{REFERENSI}

Saifi, Muhammad \& Firda Mastuti. 2013. Analisis Z-Score Sebagai Salah Satu Metode Dalam Menganalisis Estimasi Kebangkrutan Perusahaan. Journal Fakultas Ilmu Administrasi Universitas Brawijaya. Malang.

Agnes, Sawir. 2003. Analisis Kinerja Keuangan dan Perencanaan Keuangan Perusahaan. Cetakan Kedua. Jakarta: PT. Gramedia Pustaka Utama

Altman, Edward I. 1968. Financial Ratios, Discriminant Analysis and The Prediction of Corporate Bankcrupty. Journal Of Financial, 23 (4) : 189-209.

Darsono \& Ashari, 2004, Pedoman Praktis Memahami Laporan Keuangan, Yogyakarta: Andi.

Fatmawati, Mila. 2012. Penggunaan The Zmijewski Model, The Altman Model, dan The Springate Model sebagai Prediktor Delisting. Jurnal Keuangan dan Perbankan. Volume 16.

Hanafi, Mamduh M. 2004. Analisa Laporan Keuangan. Edisi Revisi. Yogyakarta: UPP AMP YKPN.

Hanafi, Mamduh M. 2012. Manajemen Keuangan. Edisi 1. Yogyakarta: BPFE

Harahap, Sofyan Safri. 2004. Analisis Kritis atas Laporan Keuangan. Cetakan Keempat. Jakarta: Raja Grafindo Persada.

Ikatan Akuntan Indonesia, 2012. Standar Akuntansi Keuangan. Jakarta: Erlangga.

Lesmana, Rico. 2003. Pedoman Menilai Kinerja Untuk Perusahaan Tbk, Yayasan, BUMN, BUMD, dan Organisasi Lainnya. Edisi Pertama. Jakarta: Elex Media Komputindo.

Megasari, Dyah. 2012. Bumi Resources di Ujung Kebangkrutan Finansial? URL: http://investasi.kontan.co.id/news/inikah-detik-detik-kebangkrutan-finansial-bumi

Munawir S., 2002. Analisis Laporan Keuangan. Edisi Keempat. Yogyakarta. Penerbit Liberty.

Nazir, Moch. 2003. Metode Penelitian Bisnis. Jakarta: Ghalia Indonesia

Sugiyono. 2012. Statistik Untuk Penelitian. Bandung : CV Alfabeta.

Siahaan, Surta. 2013. Prospek Penghuni Baru Indeks LQ45.

Rizkia, Meita 2013. Pengaruh BETA, SIZE dan Debt Ratio Terhadap Return Saham Pada Perusahaan-Perusahaan pertambangan yang Termasuk ke dalam LQ-45 Periode 2008-2012. Skripsi Akuntansi Program Sarjana Akuntansi Fakultas Ekonomi Universitas Widyatama: tidak diterbitkan.

Nurmayangsari, Astrid. 2012. Analisis Rasio Keuangan Untuk Memprediksi Kebangkrutan Perusahaan (Survei pada Perusahaan Alas Kaki yang Terdaftar dii Bursa Efek Indonesia Tahun 2007-2010). Skripsi Akuntansi Program Sarjana Akuntansi Fakultas Ekonomi Universitas Widyatama: tidak diterbitkan.

URL: http://investasi.kontan.co.id/news/prospek-penghuni-baru-indeks-lq45

www.markets.ft.com 